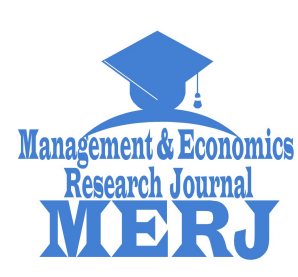

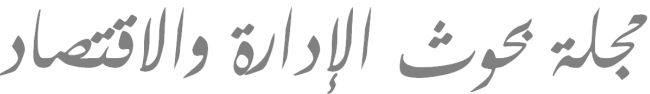

Management \& Economics Research Journal ISSN 2710-8856 (Online)

ISSN 2676-184X (Print)

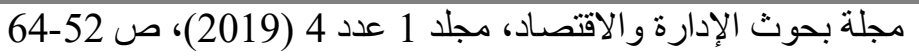

Management \& Economics Research Journal, Vol. 1 No. 4 (2019), pp. 52-64 do) https://doi.org/10.48100/merj.v1i4.61

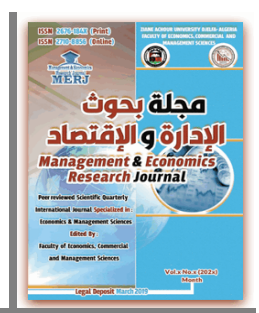

\section{الاقتصاد السياسي لإصلاح السياسة التجارية في الجزائر: خلال الفترة 2018-1990}

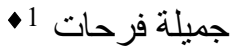 \\ 1 طالبة دكتور اه، جامعة و هران 2 محمد بن أحمد (الجزائر ) \\ $ه$ ferhat.doctor31@gmail.com
}

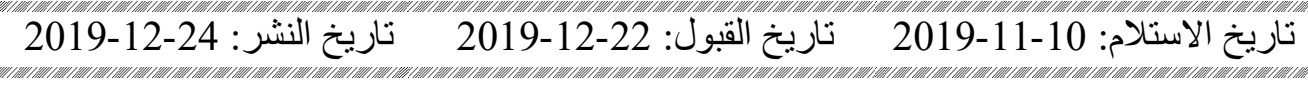

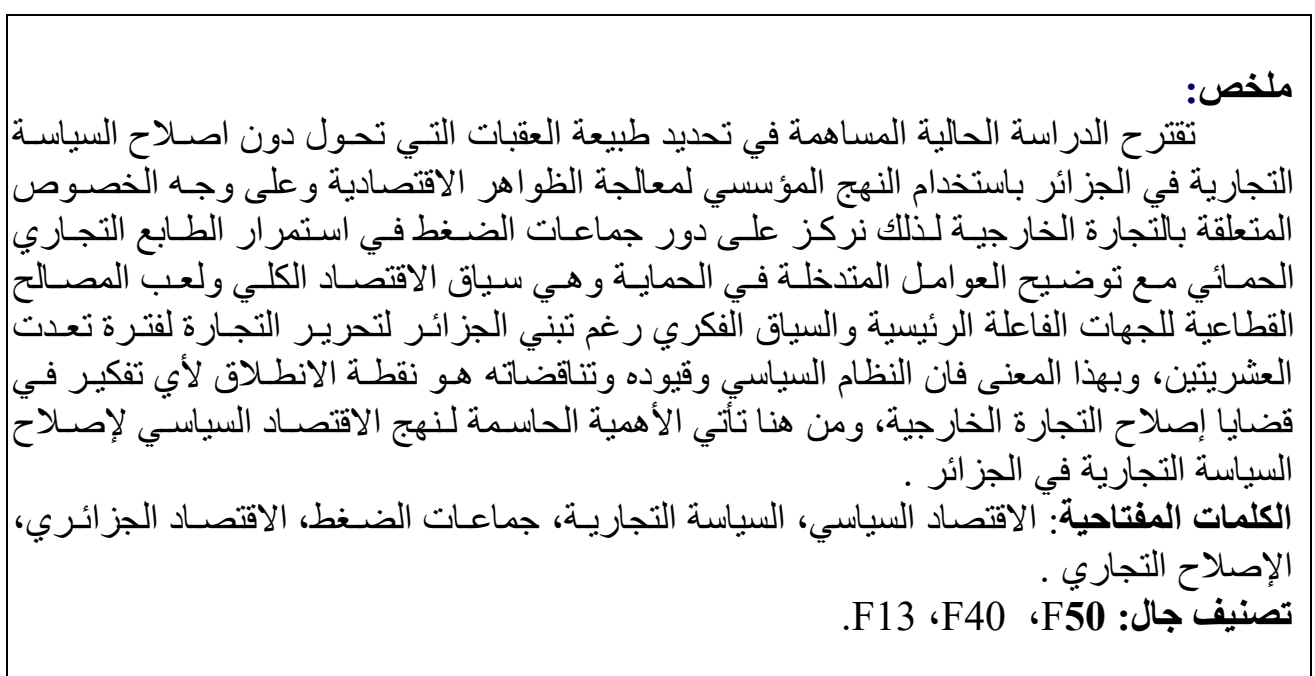

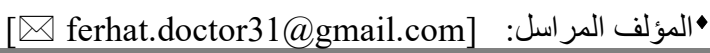




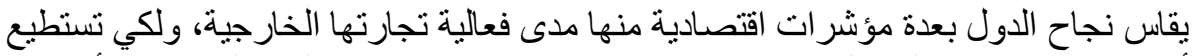

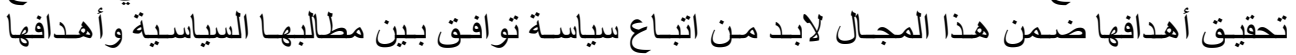

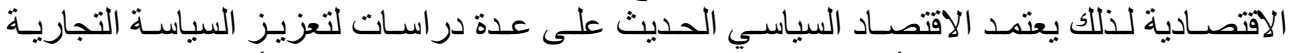

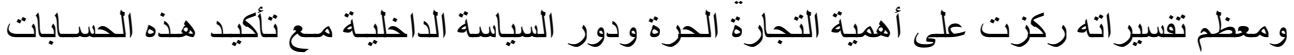

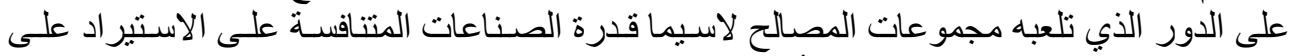

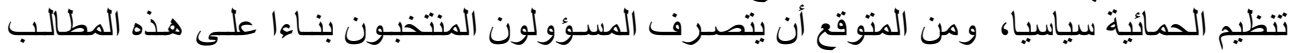

باستعمال عدة حجج منها جانب الطلب و الذي يعتبر جو هر الاقتصاد التباد السياسي للسياسة التجارية.

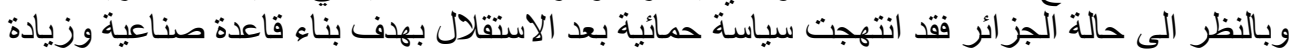

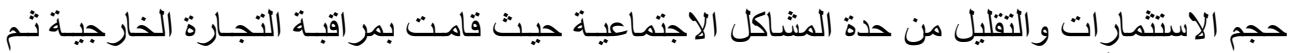

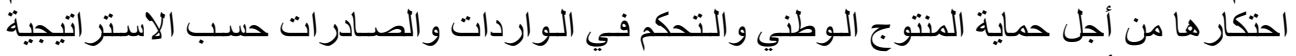

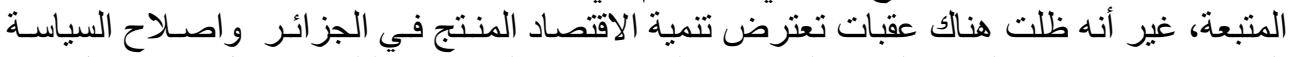

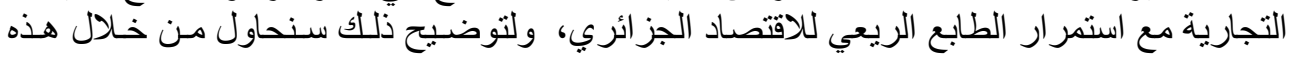

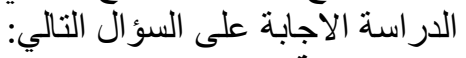
1.1 مـا مـدى تـأثير جماعـات المصـالح السياسـية على فعاليـة اصـلاح السياسـة التجاريـة في

2.1

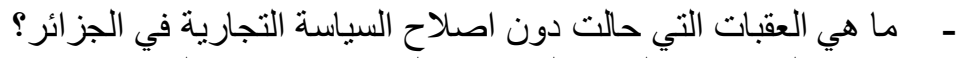

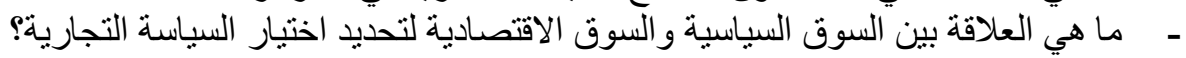

3.1

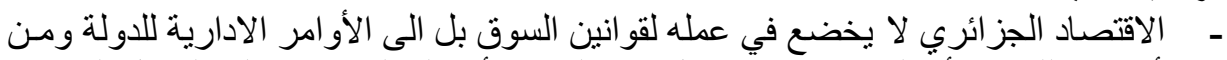

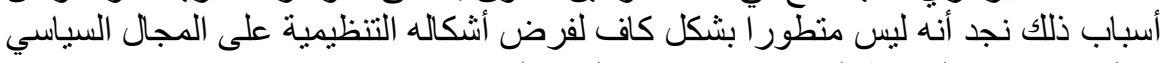

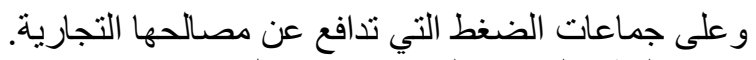

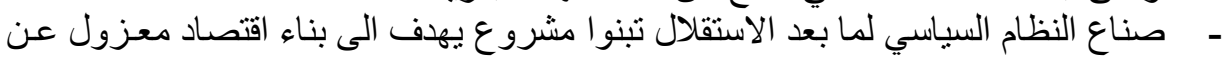

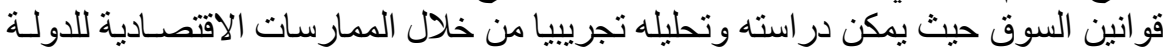

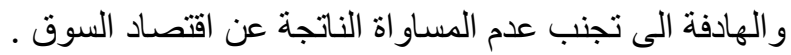

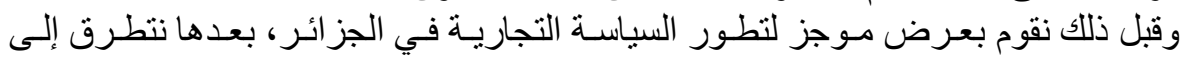

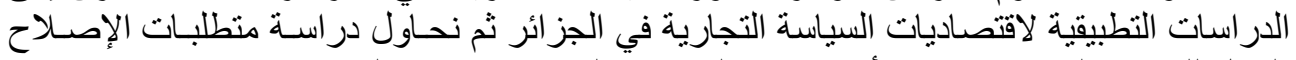

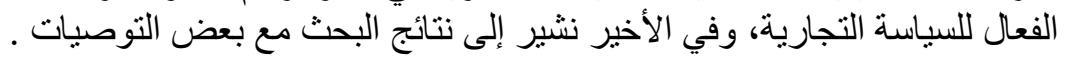

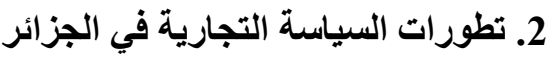

عرفت الجز ائر وكغير ها من الدول النامية بعد الاستقلال عدة اجر اءات وتدابير لتنظيم قطـاع

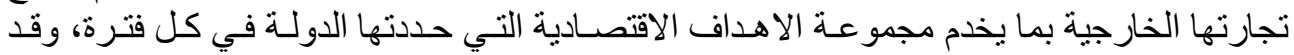

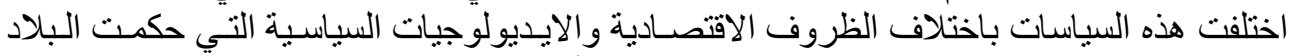

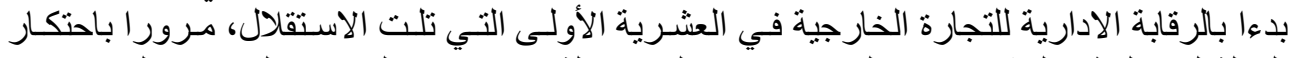

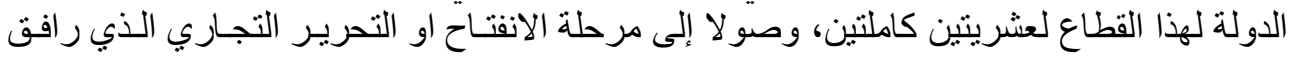


الانفتاح السياسي والاقتصادي الذي تم تبنيه في نهايـة السبعينيات وبدايـة الثمانينيـات، ويمكن إيجـاز هذه المراحل على الني والنحو النتالي:

1.2 السياسة التجارية المطبقة في الفترة قبل 1990

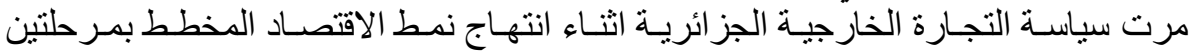

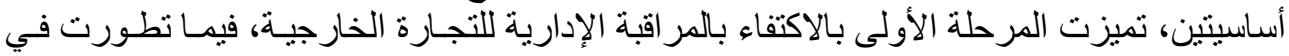

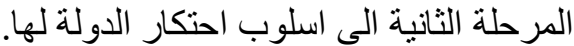

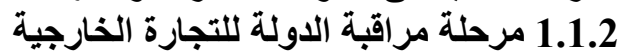

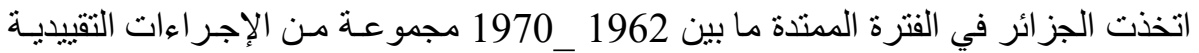

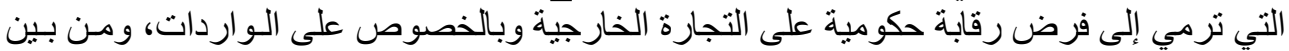

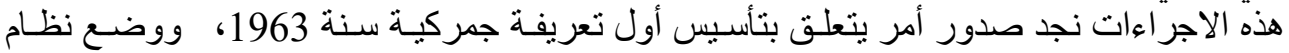

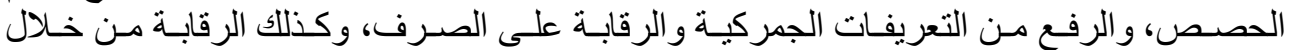

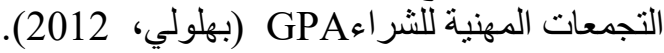

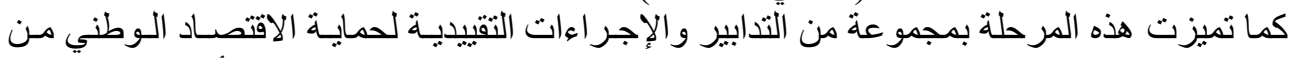

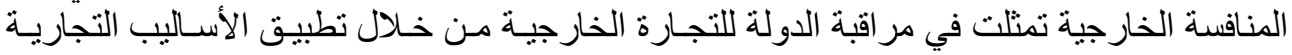

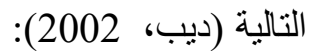

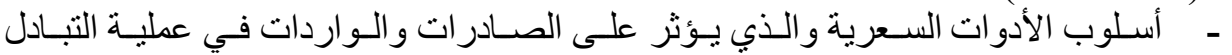

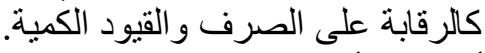

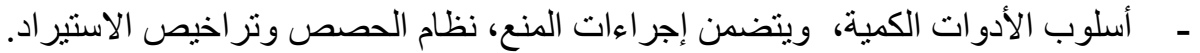

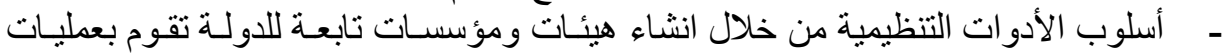

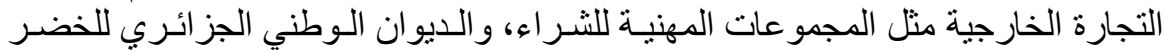

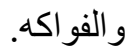

1.1.2مرحلة احتكار الدولة للتجارة الخارجية

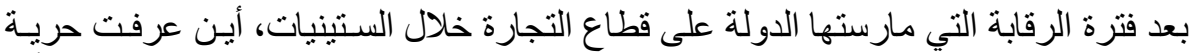

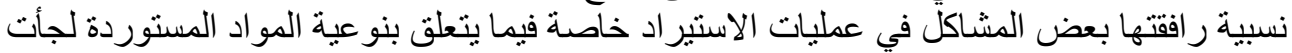

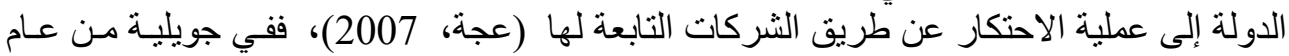

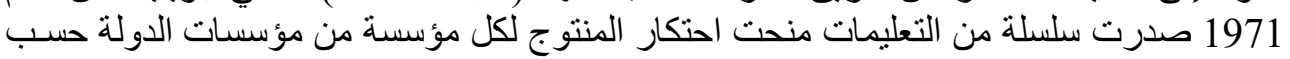
النشاط الذي تمارسه حيث كانت 80 \% م من الواردات تحت احتكات التكار المؤسسات العمومية.

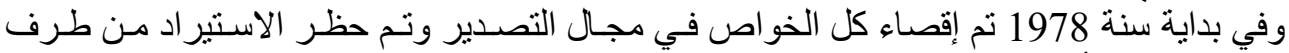

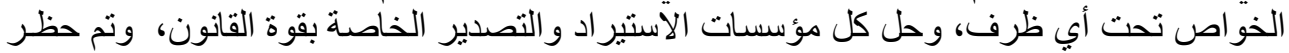

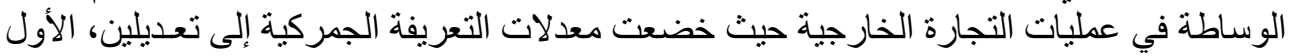

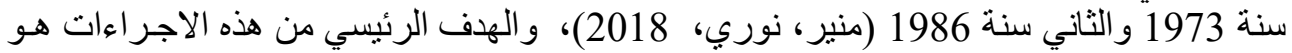

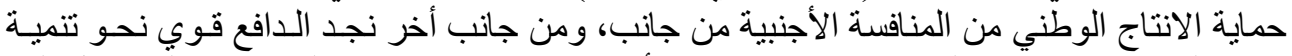

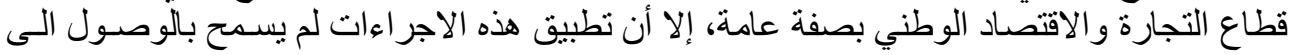

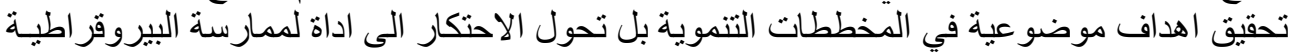

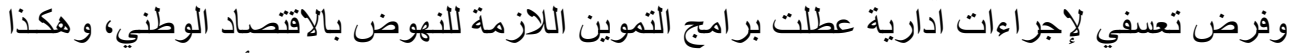

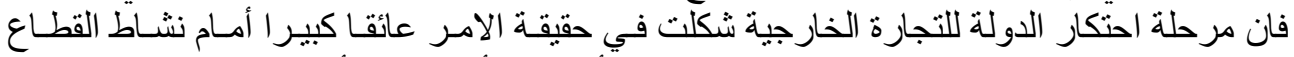

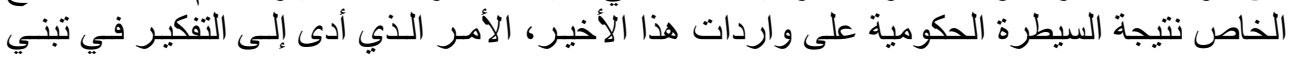

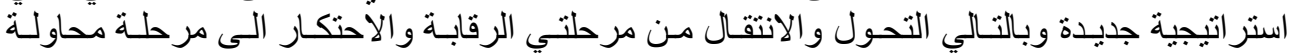

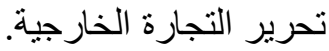


2.2 السياسة التجارية المطبقة منذ 1990

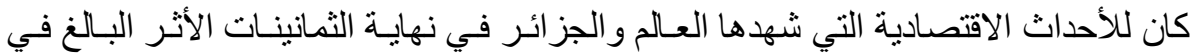

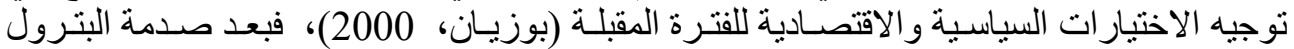

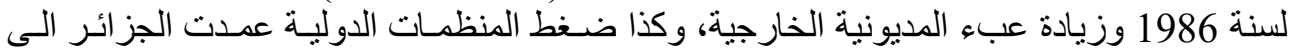

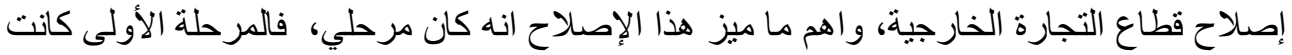

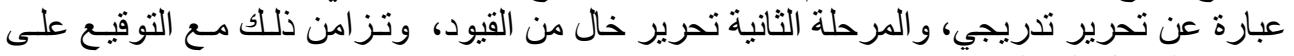

\section{1-1990 مرحلة التحرير المقيل المبل برنامج التعديل الهيكلي.}

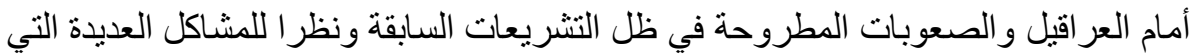

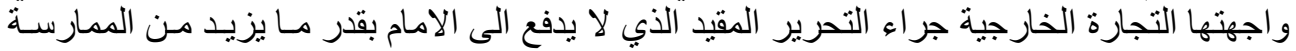

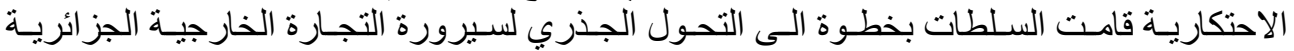

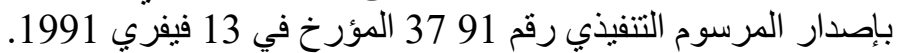

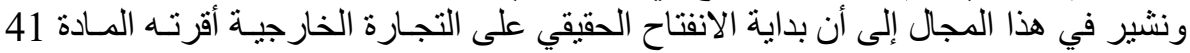

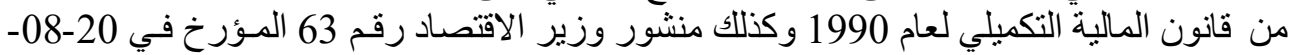

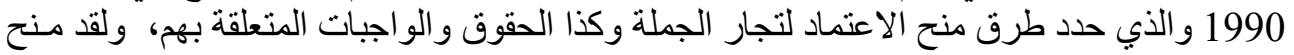

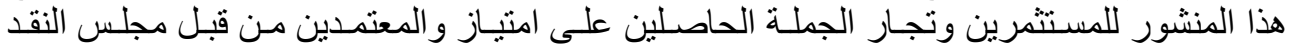

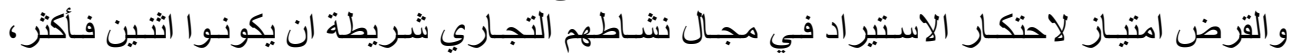

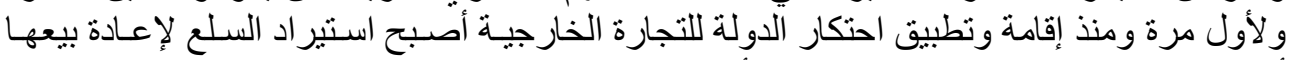

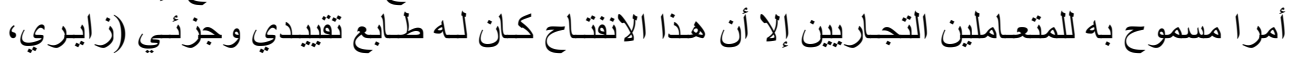

2.2.2 مرحلة تحرير التجارة الخارجية منذ 1994

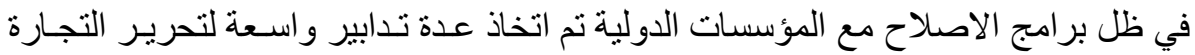

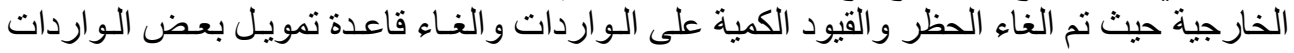

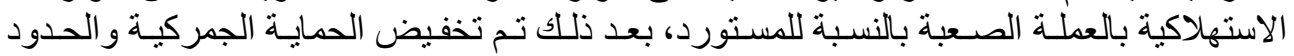

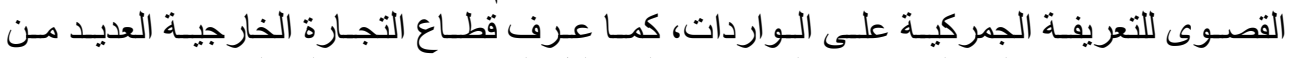

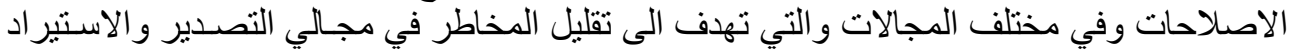

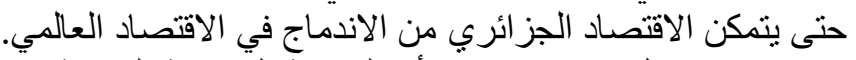

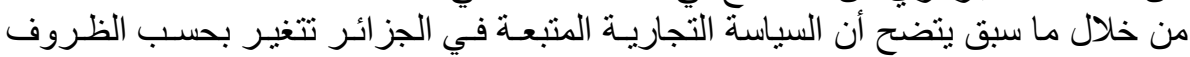

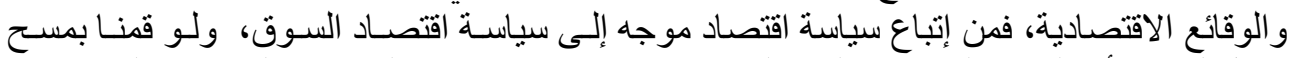

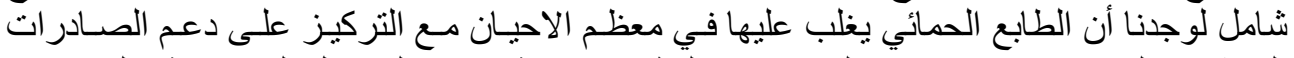

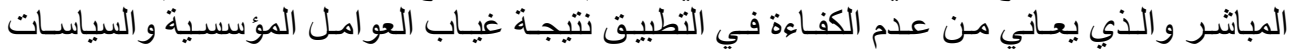

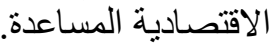

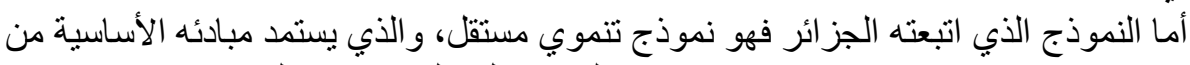

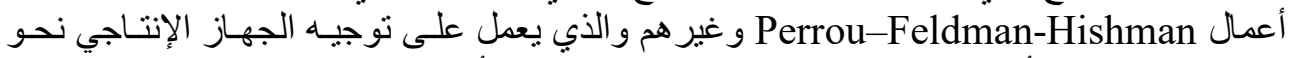

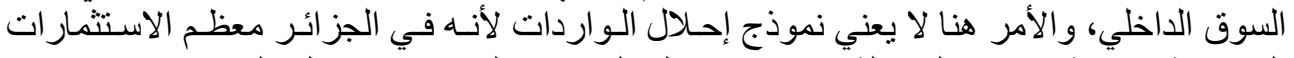

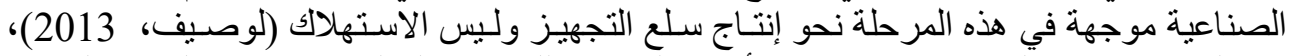

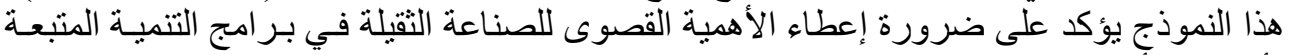

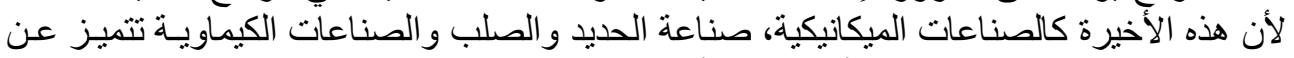

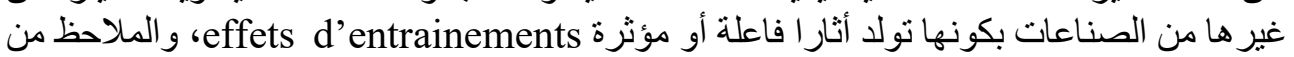

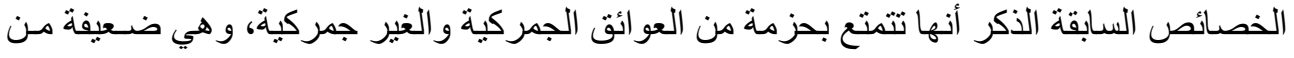




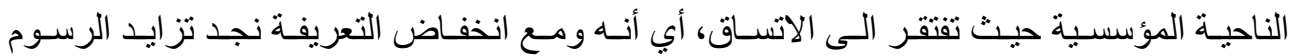

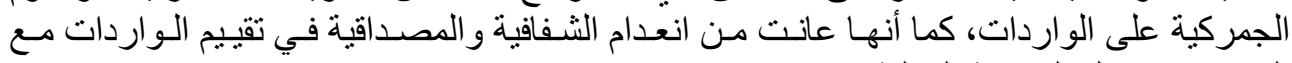
التناعب بجداول التعريفة المعلنة .

\section{3. الدراسات التطبيقية لاقتصاديات السياسة التجارية في الجزائر}

1.3 أهمية الاختيارات المنهجية في دراسة الظواهر الاقتصادية للمجتمعات غير المتمايزة

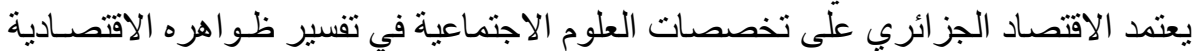

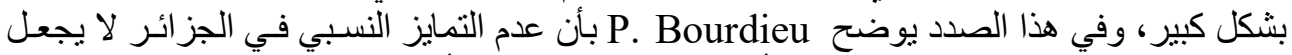

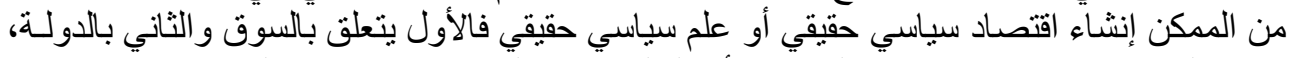

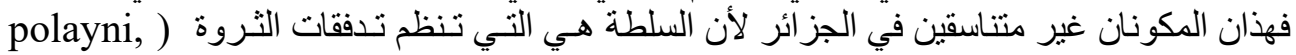

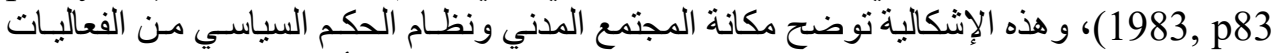

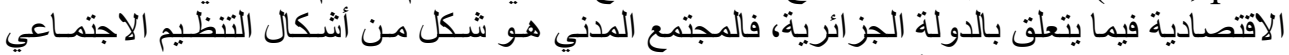

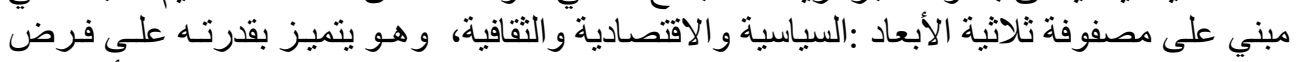

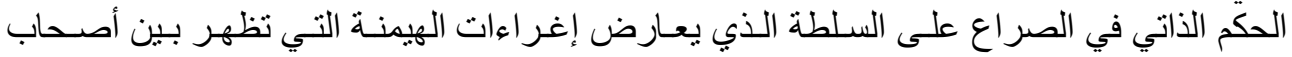

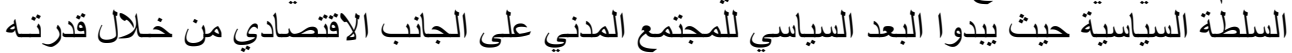

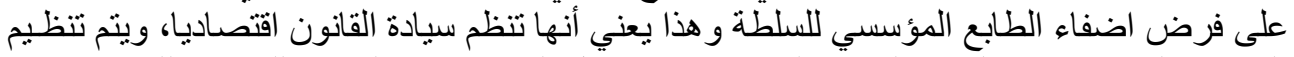

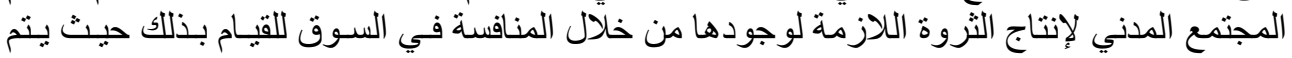

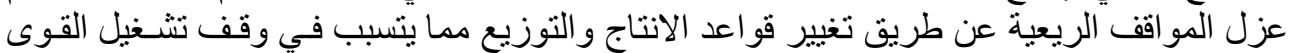

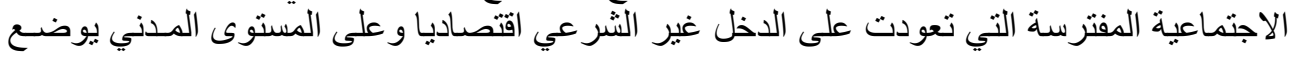
الفرد في قلب العملية الاجتماعية (Addi, 2014p11) .

2.3 أثر السوق السياسية على صياغة خيارات السياسة التئة التجارية في الجزائر:

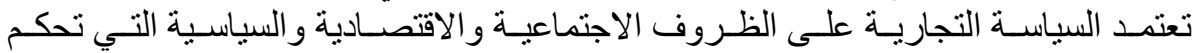

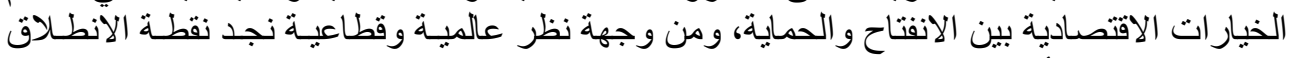

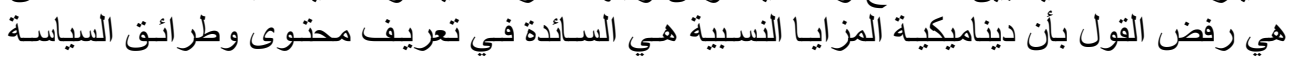

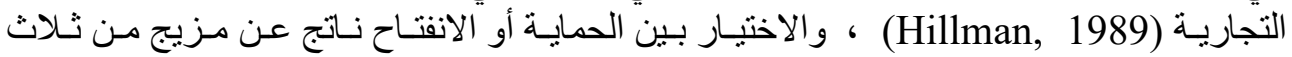

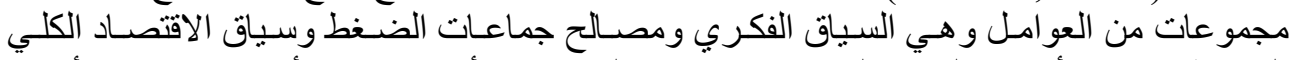

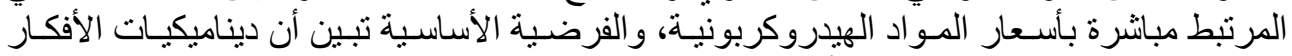

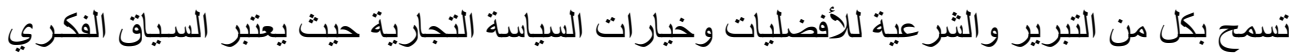

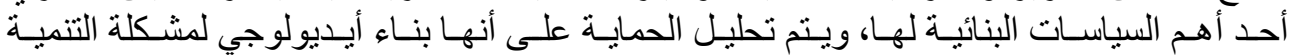

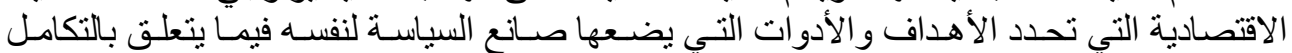

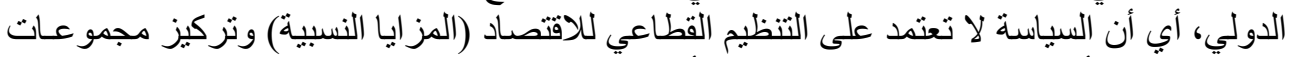

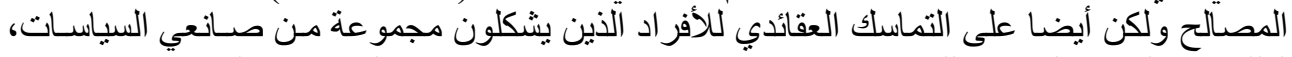

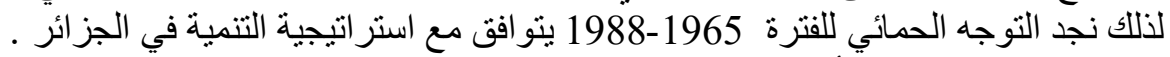
و لمعرفة درجة تأثنير السوق السياسية على فعالية السياسة التجارية في الَّزئية ائر نقوم بتحليل الثكل التالي : nen 


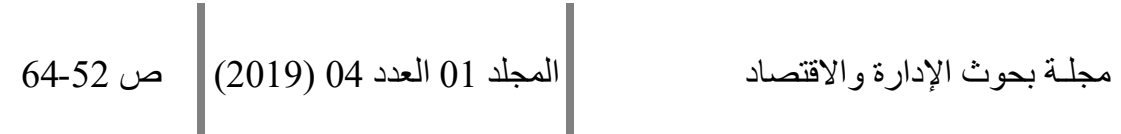

شكل رقم 1: تعريفة التوازن في السوق السياسية

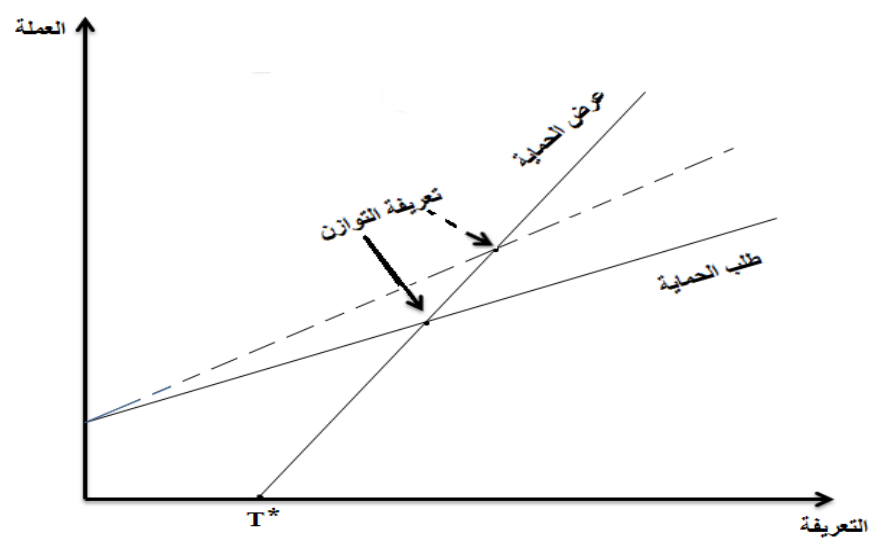

Source : (Baldwin, 2006, p 1451)

يمثل الرسم البياني مستوى التوازن في السوق السياسية، ويعرف هذا عن طريق النقطة التي : التي

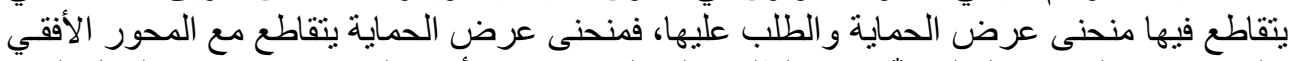

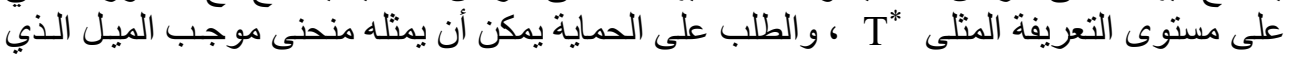

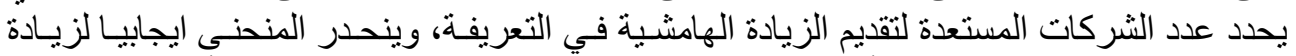

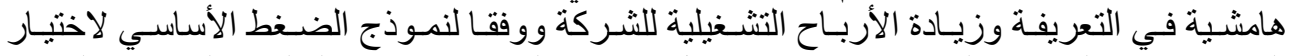

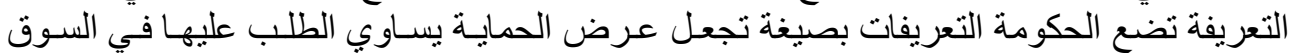

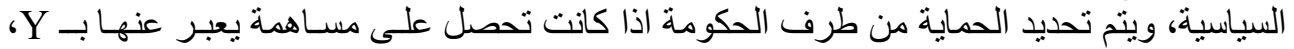

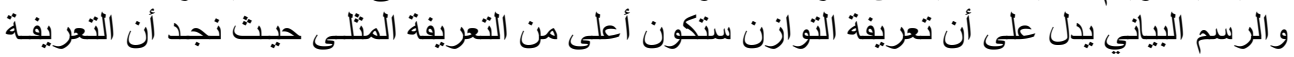

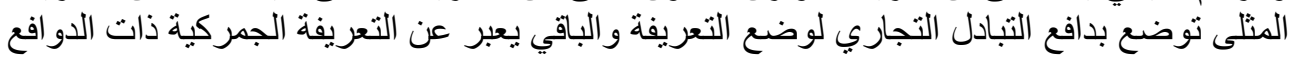
السياسية

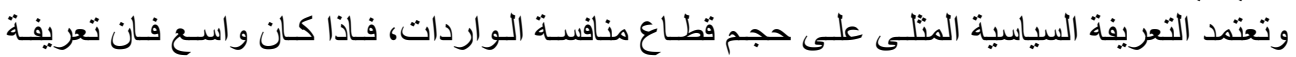

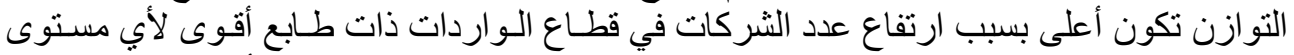

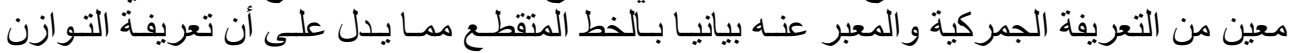

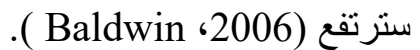
ويمكن تحليل درجة الحماية الناجمة عن الاعتبار ات السياسية بيانيا وفق الثكل 2. 
شكل رقم 2 : منحنى تكلفة الضغط لتأمين مستويات الحماية التعريفية من طرف اللوبي

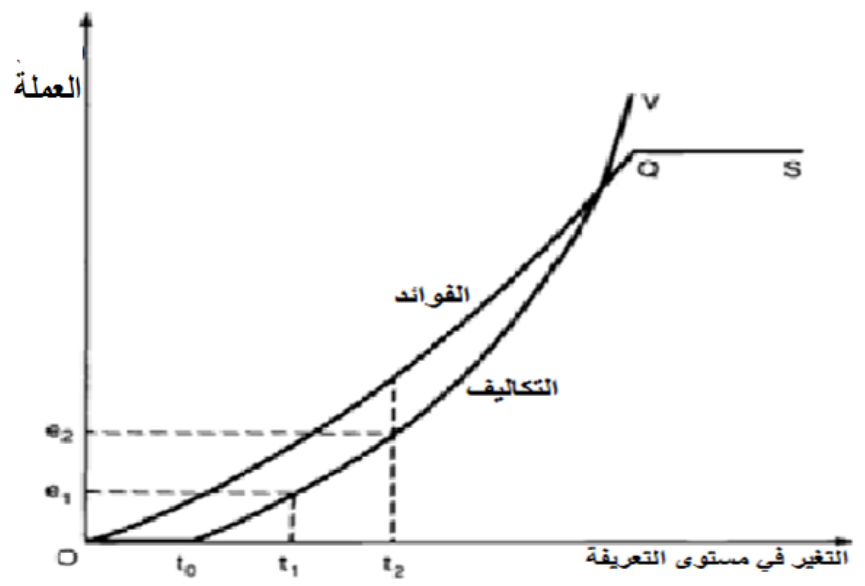

Source: (Baldwin, 1982, p 275)

يمكن تحليـل درجـة الحمايـة الناجمـة عـن الاعتبـار ات السياسـية بيانيـا وفتق الثـكل 2 حيـث OtoV

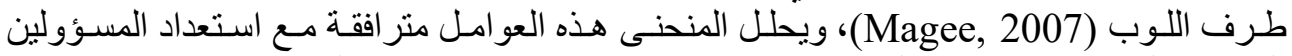

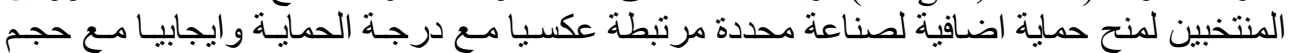

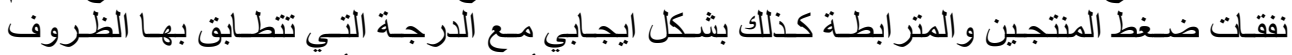

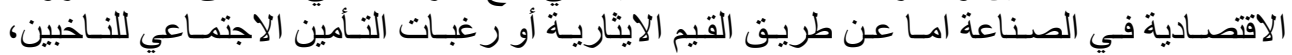

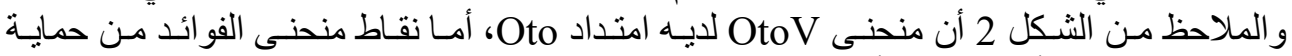

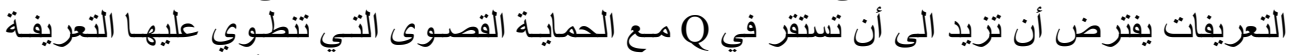

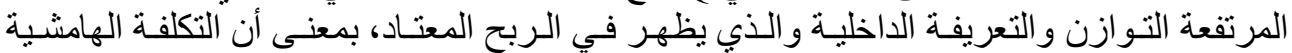

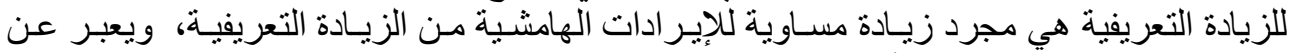

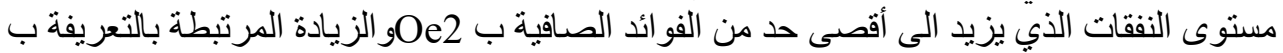

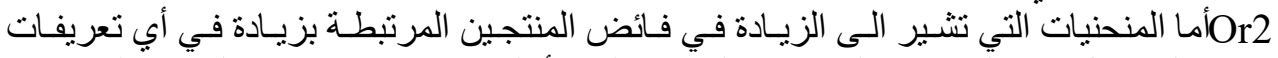

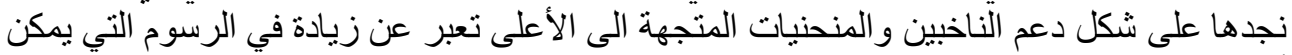

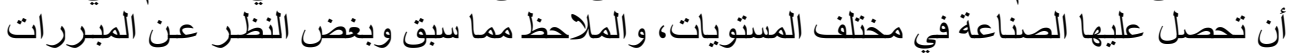

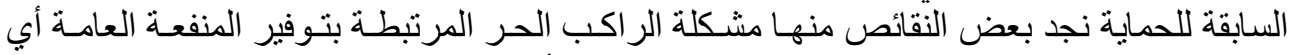

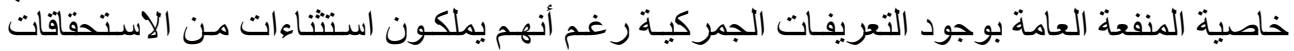

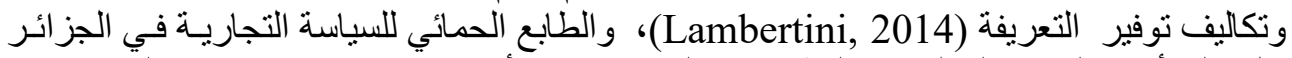
يدل على أن هنالك مصالح لبعض القطاعات والتي ستخسـر أو تـنخفض مكاسبها في حالـة الانفتـاح

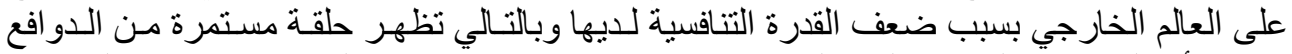

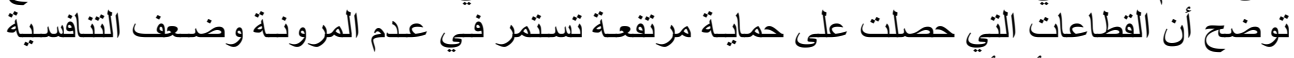

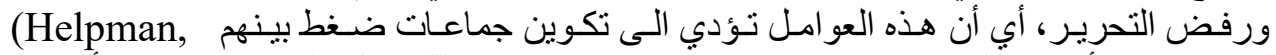

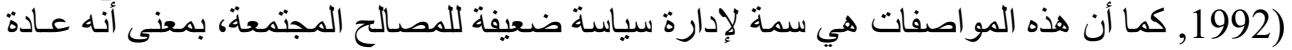

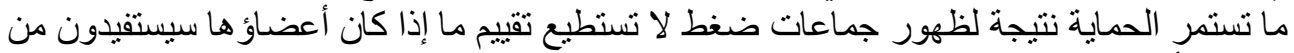

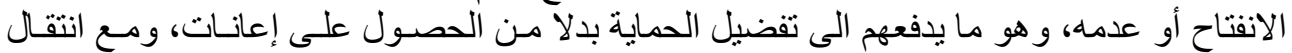

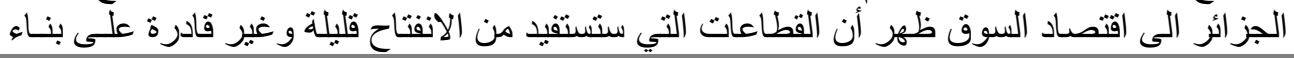




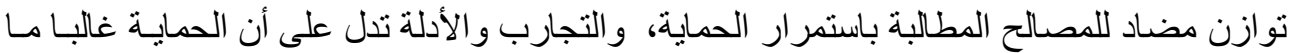

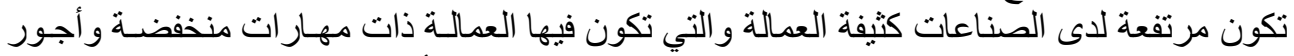

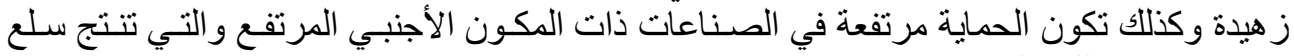
استهلاكية تستهلك على مسنوى قطري واسع رغم تمركز إنتاجها (Rodrik, 1994) .

\section{4 ـ متطلبات الاصلاح الفعال للسياسة التجارية في الجزائر}

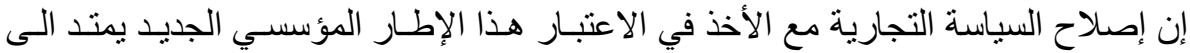

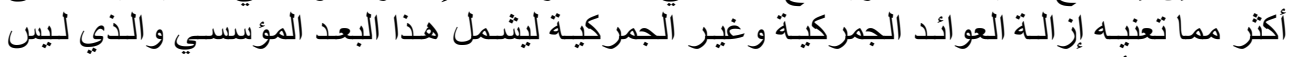

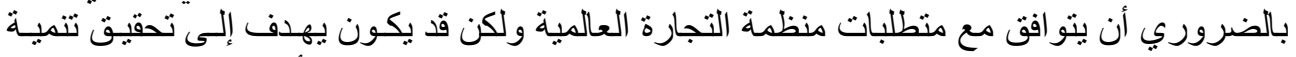

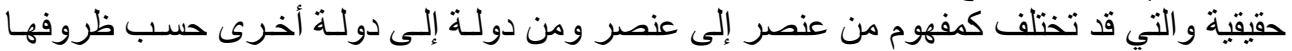

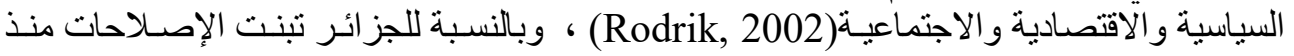

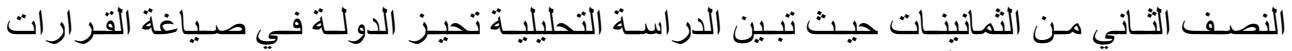

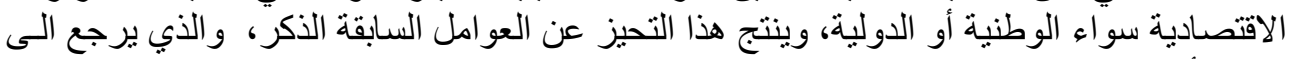

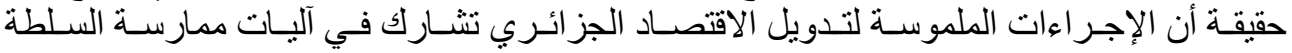

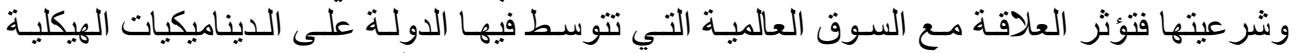

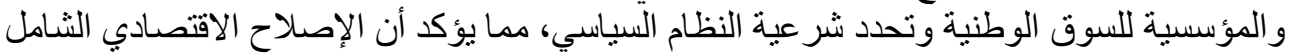

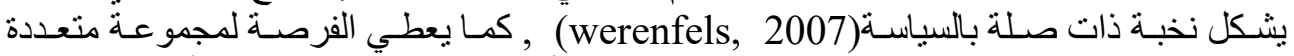

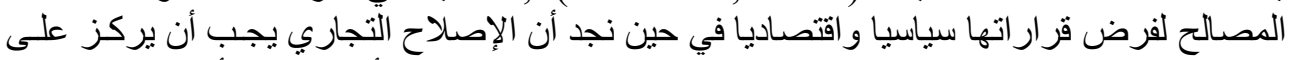

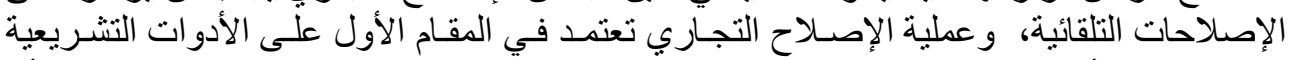

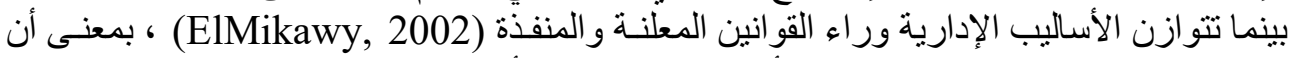

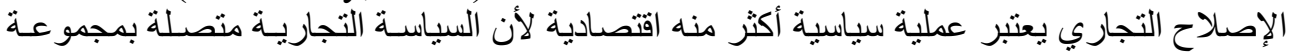

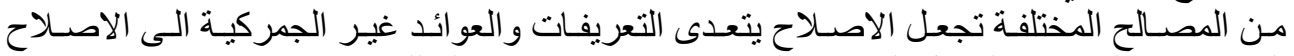

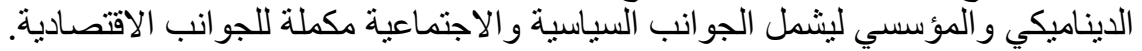

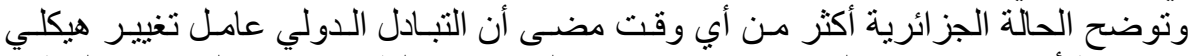

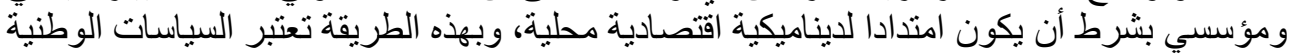

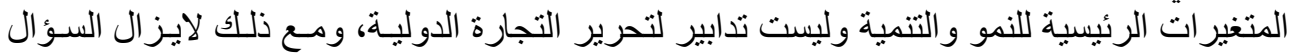

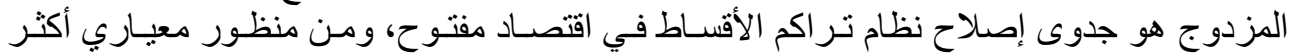

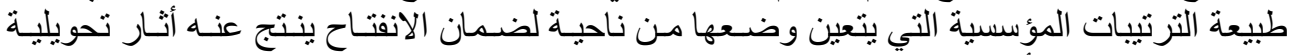

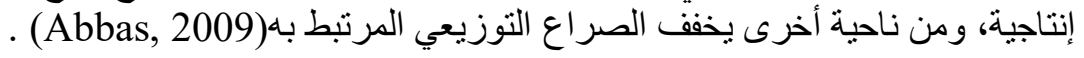


نستخلص من هذه المساهمة أن إصلاح السياسة التجارية في الجزائر يعتبر حل لجز ألجاء ضـائيل

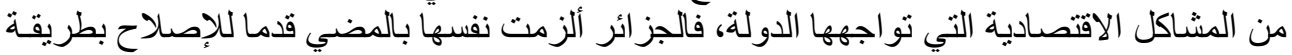

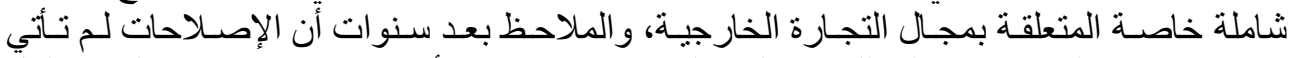

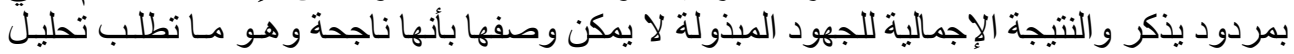

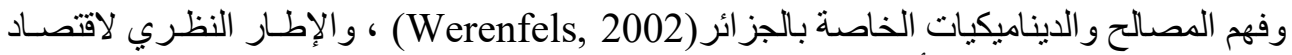

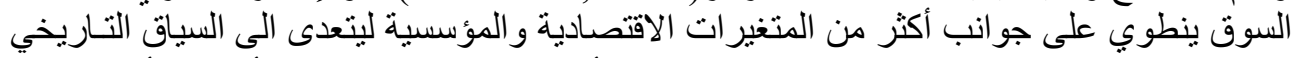

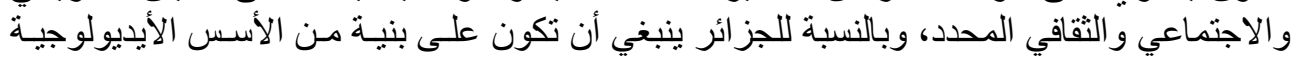

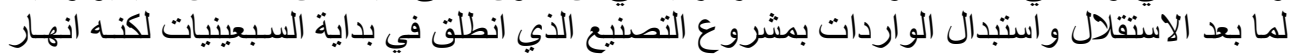

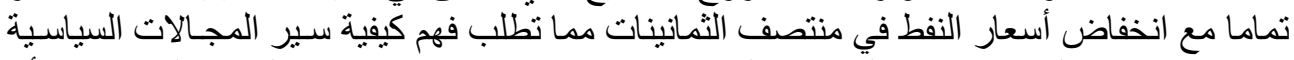

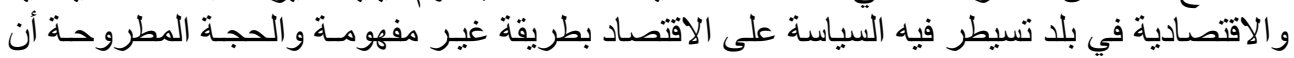

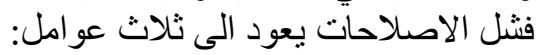

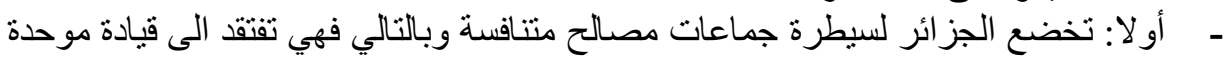

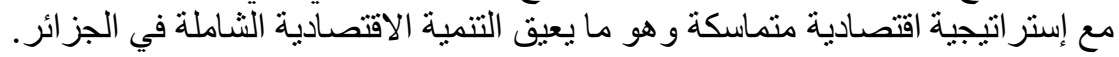

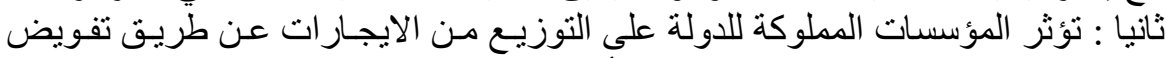

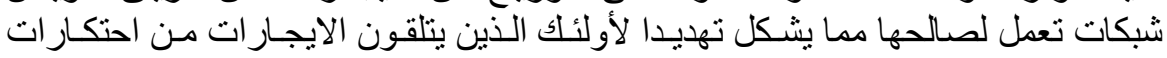

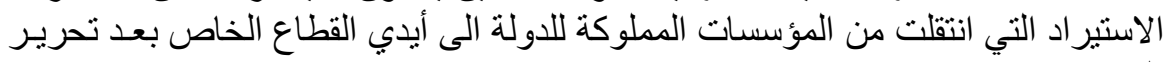
والتجارة .

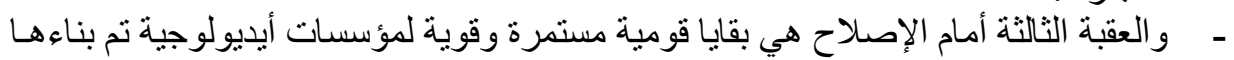

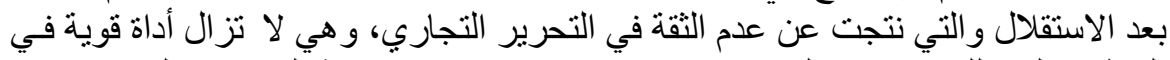

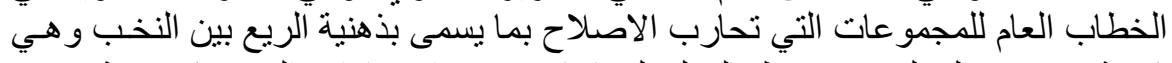

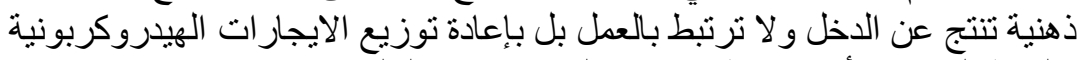

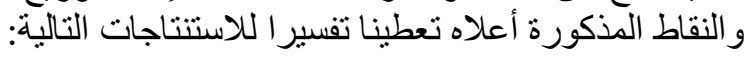

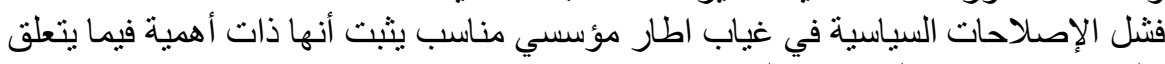

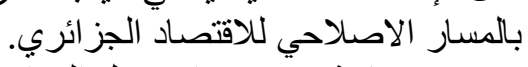

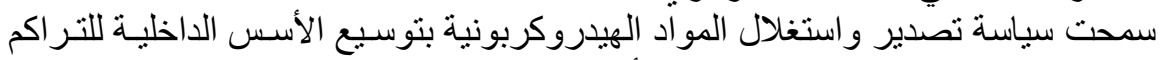
بهدف تحقيق استقلال اقتصادي وسياسي أكبر.

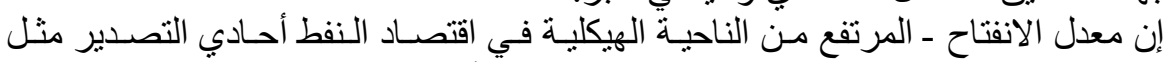

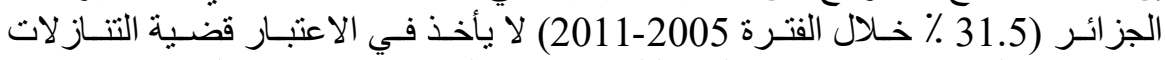

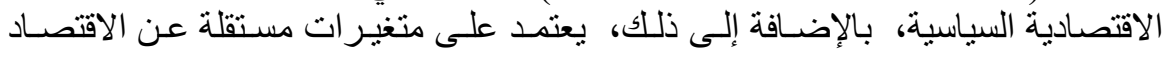

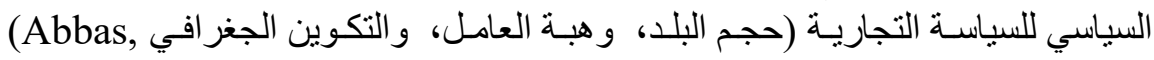
.2012)

وبناءا على ذللك نقلم مجمو عة من التوصيات أهمها ما يلي:

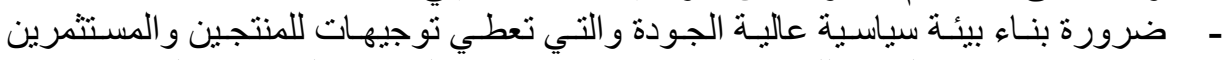

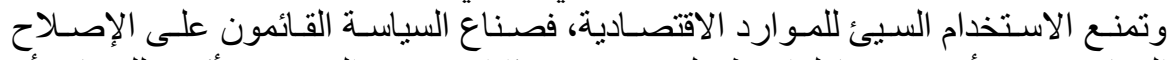

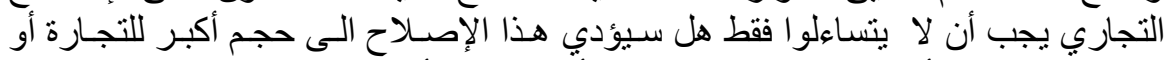

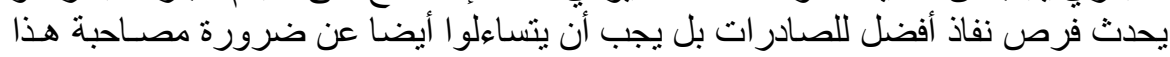
الإصلاح بيئة سياسات ذات جودة عالية داخل الوطن نفساه (Rodrik, 2002) . 


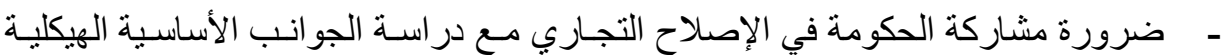

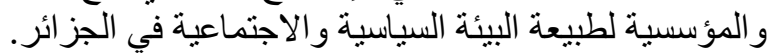

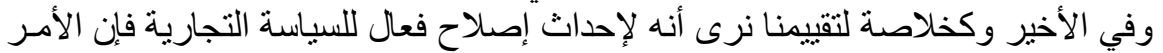

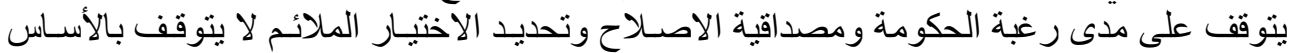
على حكم اقتصادي قوي بل يتعدى في أغلب الأحيان الى أساس سياسي.

الملاحق

الشكل رقم (3): أصحاب المصالح ومو اقفهم المختلفة فيما يختص بتحديد السياسة التجارية

\begin{tabular}{|c|c|c|}
\hline مصـادر القوة & الموقف & أصحاب المصالح \\
\hline |أقوياء من خلال غرف & ضد تحرير التجارة للخوف من المنافسة & التوارداتع لإحلال محل \\
\hline ضعفاء & مع تحرير التجارة وتتشيط الصسادر ات & |الخصدرون في القطاع \\
\hline |أتجارة من خلال غرفي الثخصي & يستفيدون من تخفيض التعريفات & |الخاصنوردون في القطاع \\
\hline 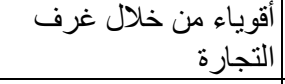 & وزيادة التنافسية إلى معارضي والذي يتر للخح بين مؤيدين آملين في التحديث & مديرو القطاع العام \\
\hline أقوياء خاصة في مرحلة & 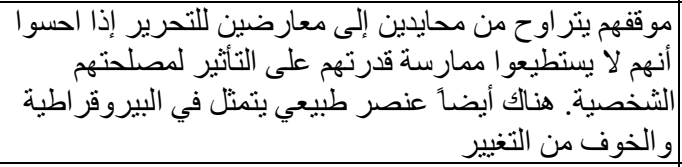 & البيروقر اطيون \\
\hline | ألقوياء من خلال & و التي قد تؤدير اللخوف بطالة. المنافسة من الواردات الرخيصة & العمالة المنظمة \\
\hline ضعيف & 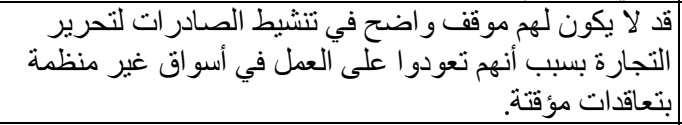 & |العمالة غير المنظمة \\
\hline ضعيف & 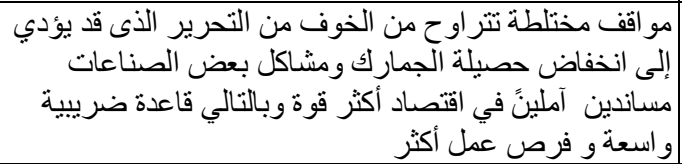 & مجلس الوزراء \\
\hline
\end{tabular}

المصدر : (مكاوي، غنيم، 2002) 
Abbas, M. (2009). L'accession à l'OMC : quelles stratégies pour quelle intégration à la mondialisation?, Confluences Méditerranée, 71.

Abbas, M. (2012). L'ouverture commerciale de l'Algérie. Apports et limites d'une approche en termes d'économie politique du protectionnisme, Revue Tiers Monde.

Addi, L. (2014). Préface, in Mourad Ouchichi, Les fondements politiques de l'économie rentière, Béjaïa, Éditions Déclic.

Baldwin, R. (1982). Import Competition and Response, Jagdish N. Bhagwati, editor University of Chicago Press.

Baldwin, R. (2006)., Multilateralising Regionalism: Spaghetti bowls as building bloc on the oath to global free trade', The World Economy, 29.

ElMikawy, N. (2002). Institutional Reform and Economic Development in Egypt, Cairo: American University Press.

Helpman, G. a. (1992). Protection for sale, Princeton University.

Hillman. (1989). The Political Economy of Protection, New York, Harwood Academic.

Lambertini. (2014). Dynamic analysis of an Electoral Campaign in Haunschmied, J, V.M. Veliov and

S. Wrzaczek (eds.), 'Dynamic Games in Economics', Dynamic Modelling and Econometrics in Economics and Finance 16, Springer.

Magee. (2007). Influence Elections, and the Value of a Vote in the U.S. House of Representatives, Economics and Politics, 19(3).

polayni, k. (1983). La Grande transformation, Paris, Gallimard. 83.

Rodrik. (1994). The rush to free trade in the developing world: Why so late? why now? will it last?' in S. Haggard and S. Webb, eds., Voting for reform: The politics of adjustment in new democracies, New York: Oxford University Press.

Rodrik. (2002). Trade policy Reform as Institutional Reform in Bernard Hoekman Handbook on Developing Countries and the Next Round of WTO Negotiations forthcoming.

Rodrik. (2002). Trade policy Reform as Institutional Reform in Bernard Hoekman Handbook on Developing Countries and the Next Round of WTO Negotiations forthcoming.

Werenfels. (2002). Obstacles to privatisation of state-owned industries in Algeria: the political economy of a distributive conflict, the journal of North African Studies, 7(1).

Werenfels. (2007). Managing Instability: Elites and Political Change in Algeria, Londres, Routledge. بهلولي ,ف .(2012) .التجارة الخارجية الجز ائرية بين اتفاقية الثر اكة الأورومتوسطية والانضمام الىى المنظمـة العالميـة للتجـارة،

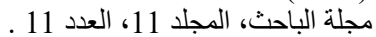

بوزيان، 1 (2000) .سياسة التصدير في الجزائر خلال مرحلـة الاقتصـاد الموجـه و الاصـلاحات، رسـالة ماجستير، كليـة العلوم

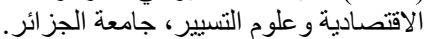

ديب، ع ـ ـ (2002) .تنظيم وتطور التجارة الخارجية، دراسة حالة الجز ائر ، أطروحة دكتور اه، كلية العلوم الاقتصسادية و التسيير ، جامعة الجز ائر.

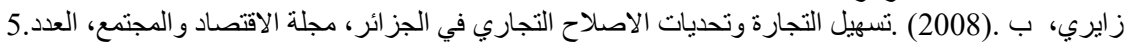

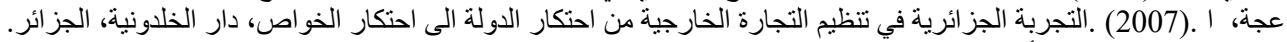

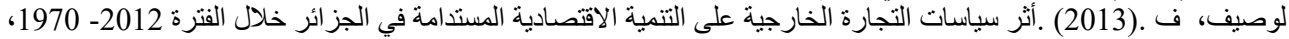

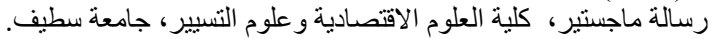

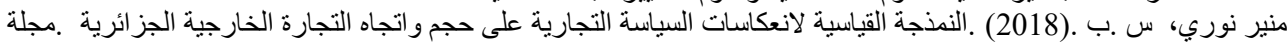

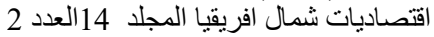
مكاوي نهى، غنيم أحمد .(2002). الاقتصاد السياسي للسياسة التجارية في مصر.

\section{References:}

Abbas, M. (2009). L'accession à l'OMC : quelles stratégies pour quelle intégration à la mondialisation?, Confluences Méditerranée, 71.

Abbas, M. (2012). L'ouverture commerciale de l'Algérie. Apports et limites d'une approche en termes d'économie politique du protectionnisme, Revue Tiers Monde.

Addi, L. (2014). Préface, in Mourad Ouchichi, Les fondements politiques de l'économie rentière, Béjaïa, Éditions Déclic. 


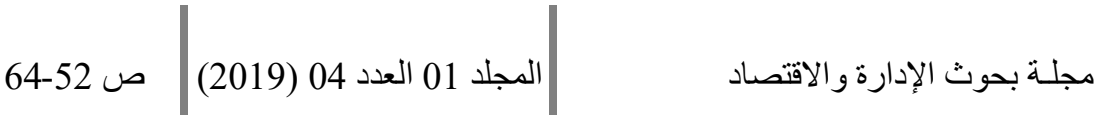

Baldwin, R. (1982). Import Competition and Response, Jagdish N. Bhagwati, editor University of Chicago Press.

Baldwin, R. (2006)., Multilateralising Regionalism: Spaghetti bowls as building bloc on the oath to global free trade', The World Economy, 29.

ElMikawy, N. (2002). Institutional Reform and Economic Development in Egypt, Cairo: American University Press.

Helpman, G. a. (1992). Protection for sale, Princeton University.

Hillman. (1989). The Political Economy of Protection, New York, Harwood Academic.

Lambertini. (2014). Dynamic analysis of an Electoral Campaign in Haunschmied, J, V.M. Veliov and

S. Wrzaczek (eds.), 'Dynamic Games in Economics', Dynamic Modelling and Econometrics

in Economics and Finance 16, Springer.

Magee. (2007). Influence Elections, and the Value of a Vote in the U.S. House of Representatives, Economics and Politics, 19(3).

polayni, k. (1983). La Grande transformation, Paris, Gallimard. 83.

Rodrik. (1994). The rush to free trade in the developing world: Why so late? why now? will it last?' in

S. Haggard and S. Webb, eds., Voting for reform: The politics of adjustment in new democracies, New York: Oxford University Press.

Rodrik. (2002). Trade policy Reform as Institutional Reform in Bernard Hoekman Handbook on Developing Countries and the Next Round of WTO Negotiations forthcoming.

Rodrik. (2002). Trade policy Reform as Institutional Reform in Bernard Hoekman Handbook on Developing Countries and the Next Round of WTO Negotiations forthcoming.

Werenfels. (2002). Obstacles to privatisation of state-owned industries in Algeria: the political economy of a distributive conflict, the journal of North African Studies,7(1).

Werenfels. (2007). Managing Instability: Elites and Political Change in Algeria, Londres, Routledge.

Bahlouli, F. (2012). Algerian foreign trade between the Euro-Mediterranean partnership agreement and accession to World Trade Organization, Al-Bahith review, 11. [In Arabic]

Bouziane, A. (2000). Export policy in Algeria during the stage of directed economics and reforms, (Master Thesis, Algiers University). [In Arabic]

Dhib, A. A. (2002). Organization and development of foreign trade, the case study of Algeria, (PhD Thesis, Algiers University). [In Arabic]

Zairi, B. (2008). Trade facilitation and the challenges of trade reform in Algeria, Journal of Economy and Society, 5. [In Arabic]

Adja, A. (2007). The Algerian experience in organizing foreign trade from state monopoly to private monopoly, Dar Al-Khaldouni, Algeria. [In Arabic]

Loucif, F. (2013). The impact of foreign trade policies on sustainable economic development in Algeria during the period 1970 -2012, (Master Thesis, University of Setif). [In Arabic]

Nouri, M., \& Bounoua. S. (2018). Econometric modelling of trade policy implications on size and direction of Algerian foreign trade. Journal of North African Economies, 14(2). [In Arabic]

Makawi, N. \&, Ghonaim, A. (2002). The political economy of trade policy in Egypt. [In Arabic] 
الاقتصاد السياسي لإصلاح السياسة التجارية في الجزائر: خلال الفترة

The Political Economy of Trade Policy Reform in Algeria: during the Period 19902018

Djamila Ferhat ${ }^{1}$

Received: 10-11-2019

\begin{abstract}
:
This study aims to contribute to determining the nature of the obstacles to reforming trade policy in Algeria using the institutional approach to deal with economic phenomena, especially those related to foreign trade. Sectoral interests of key actors and an intellectual context despite the adoption by Algeria of trade liberalization for more than two decades in this sense, the political system, its constraints and contradictions are the starting point for any reflection on the issues of trade reform, hence the crucial importance of the approach to economic policy reform trade policy in Algeria.

Keywords: Political economy, Trade policy, Lobbyists, Algerian economy, Trade reform. JEL Classification: F13, F40, F50.
\end{abstract}

$1 \bullet$ Corresponding author: University of Oran 2 Mohamed Ben Ahmed (Algeria), [ $\bowtie$ : ferhat.doctor31@gmail.com]. 